\title{
POBLACIÓN INDÍGENA Y ETNOHISTORIA EN EL EXTREMO ORIENTAL DE VENEZUELA
}

\author{
Nelly Velázquez
}

Resumen: El presente artículo tiene como propósito estudiar las características socioculturales y la historia de la población indígena del extremo oriental de Venezuela, específicamente del golfo de Paria, con la cual Colón entró en contacto en su tercer viaje. Para ello se utilizan tres fuentes fundamentales, como la información etnológica contenidaenel relato colombino, losestudios de etnologíabasadosen los relatos de los colonizadores (expedicionarios, cronistas y misioneros) realizados en la zona del oriente venezolano y las Antillas (Acosta Saignes, 1961; Civrieux, 1980; Salas, 1971), a las que se añaden las fuentes arqueológicas (Cruxenty Rouse, 1961; Sanojay Vargas, 1974).

Palabras clave: Etnohistoria, indígenas, colonización, Paria y Venezuela.

Enviado a dictamen: 14 de julio de 2010

Aprobación: 10 de septiembre de 2010

Revisiones: 1

Nelly Velásquez, Universidad de Los Andes (Venezuela), Facultad de Humanidades y Educación. Departamento de Antropología y Sociología. E-mail: gisara@ula.ve.
Abstract: This paper aims to study the cultural characteristics and history of the indigenous population of eastern Venezuela, specifically the Gulf of Paria, in which Columbus made contact on his third voyage. This uses three main sources, such as ethnological information contained in the story of Columbus, ethnology studies based on the stories of the settlers (explorers, writers and missionaries) made in the area of eastern Venezuela and the Antilles (Acosta Saignes, 1961; Civrieux, 1980; Salas, 1971), which are added to the archaeological sources (Cruxent and Rouse, 1961; Sanoja and Vargas, 1974)

Keywords: Ethnohistory, indigenous peoples, colonization, Paria and Venezuela

\section{Introducción}

L a historia de las poblaciones indígenas que habitaban el extremo oriental de Venezuela a la llegada de los colonizadores se ha caracterizado por tergiversaciones y falseamientos resultantes de las visiones, muchas veces, sesgadas de los cronistas, en quienes se basan los estudios históricos sobre la región. Es el caso de los pobladores de Paria, que fueron identificados como "peligrosos" indígenas caribes, considerados además antropófagos, belicosos, aventureros y sanguinarios. A esto han contribuido, 
en algunos casos, la etnología antigua y la arqueología al privilegiar la cultura material como elemento para la clasificación en un área cultural específica. Ambas posturas han provocado que se tengan visiones equivocadas y generalizadas de un limitado desarrollo cultural entre estas poblaciones, más aún cuando se les compara con otras sociedades americanas de gran complejidad sociocultural. Es por ello que para tener un conocimiento más específico e integral, se propone el estudio de los pobladores del golfo de Paria como fenómenos históricos particulares que se desarrollan en un contexto natural y social y que pueden ser reconstruidos con variables como medio ambiente, organización del trabajo, instituciones sociales, tecnología, instituciones políticas, ideología y la interrelación entre sociedades (Langebaek, 1997: 2-5), a partir de la combinación de fuentes históricas, arqueológicas y etnológicas.

\section{El relato de Colón}

El descubrimiento "oficial" de las costas de lo que hoy es el territorio venezolano, de la tierra firme del continente americano (Arellano, 1986: 161), tuvo lugar durante el tercer viaje del almirante Cristóbal Colón a las Indias, realizado en 1498. El explorador recogió sus impresiones sobre este tercer viaje por escrito; en la crónica hace referencias a diversos aspectos del mismo, a los lugares recorridos y a las gentes que se encontraron. Se destaca el encuentro con indígenas en la costa de la isla de Trinidad y del golfo de Paria. Asimismo, en la relación del tercer viaje se dio cuenta de las características físicas y culturales de la población autóctona que habitaba la zona costera e insular del noreste de América del Sur.

La mayor información etnológica sobre la población autóctona de la costa de Trinidad y el golfo de Paria contenida en la crónica del almirante está resumida en tan sólo cuatro párrafos. Parece poca cantidad pero - en nuestro criterio - es importante, tanto en calidad como en cantidad. Son los siguientes:
1. En el primer párrafo seleccionado se refiere a los alrededores del sitio que Colón denominó Punta de Arenal, en la isla de Trinidad:

... El día siguiente vino de hazia Oriente una gran canoa con veinte cuatro hombres, todos mancebos e muy ataviados de armas, arcos y flechas y tablachinas, y ellos, como dixe, todos mancebos de buena disposición y no negros, salvo más blancos que otros que aya visto en las Indias, y de muy lindo gesto y fermosos cuerpos y los cabellos largos y llanos cortados a la guisa de Castillas y traían la cabeza atada con un pañuelo de algodón, tejido a labores y colores, el cual creía yo que era almaizar; y otro d estos pañuelos traían ceñido e se cobijaban con él en lugar de pañetes (Colón, 1989: 207).

Nótese en el texto que a primera vista Colón identifica las características físicas, donde resalta la belleza corporal de los individuos. Igualmente Colón establece diferencias en el color de la piel entre estos indígenas que poblaban la costa de Trinidad y los habitantes de las islas de las Antillas Menores y Mayores, en especial Cuba y La Española, ya visitadas en los viajes anteriores.

En cuanto al aspecto cultural de la población, resalta el uso de armas como arcos, flechas y tablachinas; ${ }^{2}$ rasgo cultural característico de las tribus caribanas que poblaban el norte de Venezuela, así como gran parte de la costa central, del oriente de Venezuela y las riberas del río Orinoco (Civrieux, 1980: 40). Otro de los rasgos resaltados en el relato de Colón son los atuendos indígenas fabricados en algodón y teñidos con colores. Los estudios etnohistóricos sobre la población autóctona de la costa de Venezuela dan cuenta de la práctica de la fabricación de sus vestidos y enseres con la referida planta autóctona, y del uso de plantas tintóreas como la guarema para la decoración de las piezas (Sanoja y Vargas, 1974: 103).

Morison ${ }^{3}$ pone en duda que el primer encuentro entre Colón y la población autóctona, durante el tercer 
viaje, se hubiera realizado en la isla de Trinidad. Según el referido autor este encuentro tuvo lugar en el otro lado del golfo, donde el almirante estableció una relación más amistosa con los indios. Al respecto señala: “... Excepto por una canoa, que se acercó y nunca retornó, los españoles no vieron nativos en Trinidad; para desconsuelo de los marinos que esperaban refocilarse con las muchachas" (Samuel Eliot Morison, citado por Raggi, 1973: 22-28). En el caso de Trinidad no hubo ningún contacto entre Colón y la población indígena que habitaba en la isla, y fue con las expediciones de los ingleses realizadas posteriormente, como la de Sir Walter Raleigh a las Antillas Menores en 1495, que se pudo tener información acerca de los habitantes de Trinidad.

2. En el siguiente párrafo del relato de Colón, se narra que navegó hacia el poniente y llegó a la costa de la tierra denominada por los autóctonos Paria, de allí continuó navegando en la misma dirección hasta llegar al sitio denominado por el almirante "del Aguja", en donde refiere el encuentro con numerosos indígenas pobladores de la zona:

... Llegué allí una mañana a ora de tercia, y por ver esta verdura y esta hermosura acordé surgir y ver esta gente, de los cuales luego vinieron en canoas a la nao a rogarme de parte de su rey, que descendiese en tierra. E cuando vieron que no curé de ellos, vinieron a la nao infinitissimos en canoas, y muchos traían piezas de oro al pescueço y algunos atados a los braços algunas perlas... (Colón, 1989: 209).

En el párrafo anterior se resalta la interpretación que hizo Colón del sistema político de los autóctonos, proyectando sus propias estructuras políticas sobre la sociedad indígena. De acuerdo con esta interpretación del sistema político autóctono, el mismo estaba integrado por poderosos y tiránicos "caciques" o "reyes". Esta interpretación eurocéntrica de la estructura política indígena se mantuvo entre los cronistas, como
Aguado, Fernández de Oviedo y Castellanos. Sin embargo, posteriormente los estudios arqueológicos y etnohistóricos refutan la existencia generalizada de un sistema político jerarquizado y rígido entre la población indígena del oriente de Venezuela (Civrieux, 1980: 146; Sanoja y Vargas, 1974: 164).

Nótese también en el relato de Colón la especial mención que tienen los atuendos indígenas fabricados en oro, debido al interés primordial de la búsqueda de este material que había motivado la expedición. Los indígenas de la costa norte de Venezuela obtenían las piezas de oro del intenso intercambio comercial que se realizaba entre los diferentes grupos étnicos de la costa de Sudamérica (Civrieux, 1980: 169). Las piezas de orfebrería debieron tener como origen zonas muy lejanas como Panamá y el extremo norte de Colombia. En la cordillera de Santa Marta, en Colombia, la cultura tairona desarrolló una importante industria del oro (Lehmann, 1973: 82).

También el almirante señala el uso de perlas como material decorativo de los indígenas. La codicia de las perlas entre los colonizadores se inició desde el segundo viaje, cuando Colón tuvo noticias de la existencia de la isla de Cubagua, y fue la búsqueda de la referida isla una de las principales causas que motivaron la realización del tercer viaje de Colón a las Indias (Manzano, 1972: 124).

3. En el tercer párrafo Colón transcribe los testimonios de los españoles que envió a tierra y establecieron un contacto más dilatado con los indígenas.

Esta gente es muy mucha y toda de muy buen parecer, de la misma color que los otros de antes y muy tratables; la gente nuestra que fue a tierra los hallaron tan convenibles, y los recibieron muy honradamente. Dizen que, luego que llegaron las barcas a tierra, que vinieron dos personas principales con todo el pueblo, creen que uno el padre y el otro era su hijo, y los llevaron a una casa muy grande, hecha a dos aguas y no redonda como 
tienda de campo, como son estas otras, y allí tenían muchas sillas, adonde los ficieron assentar, y otras adonde ellos se assentaron, y hizieron traer pan y (de muchas maneras frutas e) vino de muchas (maneras frutas), blanco e tinto, mas no de uvas. Debeél de ser de diversas maneras, uno de una fruta y el otro de otra, y asimismo debe ser de déllo de mahiz, que es una simiente que haze una espiga como una mocorca, de que llevé yo allá, y ay ya mucho en Castilla; y parece que aquel lo que tenía mejor, lo traía por mayor excelencia y lo dava en gran precio. Los hombres todos estaban juntos a un cabo de la casa y las mugeres en otro. Recibieron ambas las partes gran pena porque no se entendían, ellos para preguntar a los otros de nuestra patria, y los nuestros por saber de la suya. E después que ovieron rescebido colación allí en casa del más viejo, los llevó el moco a la suya e fizo otro tanto, e después se pusieron en las barcas e se vinieron a la nao (Colón, 1989: 209-210).

En este párrafo del relato de Colón se encuentra la mayor cantidad de información etnológica sobre la población indígena del golfo de Paria. En el mismo se deduce que la población ubicada más al interior del golfo pertenecía al mismo grupo étnico de los otros indígenas encontrados en la costa, debido a las semejanzas de los rasgos físicos y culturales entre ambas poblaciones.

Otro elemento de resaltar en la carta de Colón es el elevado número de indígenas existentes en el lugar. El mantenimiento de una elevada población obedeció a la existencia de una amplia base de recursos alimenticios resultantes de las diversas actividades económicas que practicaba la población, entre los cuales estaban la agricultura, pesca, caza y recolección. También las favorables condiciones ecológicas, en cuanto a la calidad de los suelos y el régimen de lluvias existentes en el golfo de Paria, hacían posible la obtención de abundantes alimentos por parte de los indígenas que habitaban el lugar (Vila, 1976: 31). Una fuente más de obtención de recursos era el intenso comercio de bienes que mantenían con las tribus vecinas y que permitía sustentar una gran población.

Un aspecto etnológico de resaltar en el relato colombino es la importancia del maíz en la dieta de la población y su utilización en la preparación de bebidas fermentadas. Este aspecto indica que la población indígena de Paria poseía una "cultura de maíz", en la cual generalmente la bebida ritual principal se fabricaba mediante la fermentación de la planta alimenticia principal (Civrieux, 1980: 156).

Un rasgo más cultural resaltado en el relato de Colón es el de las normas de comportamiento social relacionadas con el sexo, como es la separación de espacios para hombres y mujeres en las viviendas. También se resalta el aspecto correspondiente a la vivienda, referida como una gran casa rectangular, de dos aguas, que albergaba a una numerosa población (Vila, 1976: 131).

Durante el tercer viaje de Colón a América, resulta extraño el recibimiento amistoso ofrecido por la población indígena a los españoles en el golfo de Paria, después de que los conquistadores cometieran grandes desmanes y genocidio con los indígenas en La Española. ${ }^{4}$ Pese a la considerable distancia que existe entre ambas zonas, debió transmitirse la noticia de la actuación de los conquistadores, dada la gran comunicación que existía entre las poblaciones de la costa de Venezuela y las Antillas Mayores y Menores, la cual evidencian los estudios arqueológicos sobre la región (Arvelo y Wagner, 1984; Raggi, 1973; Sanoja y Vargas, 1974).

Rasgo importante del encuentro entre los conquistadores y la población autóctona de Paria fue la dificultad que tuvieron para entablar comunicación verbal. Resulta extraña la dificultad expuesta por Colón en su relato, en especial si de acuerdo con las referencias históricas en las expediciones los colonizadores iban acompañados de indígenas que les servían de intérpretes. Lo anterior hace pensar que los habitantes de Paria debían hablar un idioma diferente al de los 
otros grupos étnicos que habitaban en las Antillas Mayores y Menores, ya conocidas con anterioridad por los conquistadores.

4. En el último párrafo, Colón ratifica lo que había expuesto anteriormente sobre las especiales características físicas de la población hallada en la tierra de Paria, y hace mención a las características de las embarcaciones indígenas, contrastándolas con las de los españoles:

Esta gente como ya dixe, son todos... Las canoas deellos son muy grandes, y de mejor hechura que no son estas otras, y más livianas, y en el medio de cada una tienen un apartamiento con cámara, en que vi que andavan los principales con sus mujeres (Colón, 1989: 210).

Debe resaltarse la descripción sobre las embarcaciones indígenas y la superioridad de las mismas con respecto a las naves españolas. También del relato sobre las naves de los jefes se deduce la existencia de la poligamia entre los "principales", jefes de las comunidades.

En esta primera parte del trabajo no ahondaremos sobre las características socioculturales de los indígenas del golfo de Paria, reseñadas por Colón en su carta del tercer viaje a las Indias, ya que estas serán objeto de un apartado especial -el 4- en donde se integrará la información del almirante con la información etnohistórica existente sobre la región.

\section{Derivación étnica de la población del golfo de Paria}

Acerca del origen étnico de las poblaciones que habitaban la costa de Paria en el período de contacto se han generado muchas confusiones, al igual que con el resto de las poblaciones indígenas de Venezuela, esta ha sido el resultado de las informaciones históricas distorsionadas (Zubiri, 1991: 89-96). ${ }^{5}$ Entre estas tergiversaciones se encuentra la idea de la existencia en Paria de peligrosos indígenas caribes. Desde los comienzos de la conquista de las islas del mar Caribe fueron justificados los enfrentamientos con los indígenas, argumentando la existencia de grupos guerreros denominados caribes, habitantes de las islas Carib - posteriormente reconocida como Boriquen o Puerto Rico-, identificados por el almirante Colón como miembros del señorío del Gran Khan. Los caribes navegaban en grandes canoas, portaban importantes arcos y aterrorizaban a los pobladores del área (Boletín de la Academia Puertorriqueña de la Historia, 1984: 271-276). Argumentos como este buscaban reservar estas tierras para el almirante Colón y sus descendientes e impedir la ocupación por otros colonizadores (Arellano, 1986: 165-166). Afirmaciones manipuladas han predominado en la historia de Venezuela con el objeto de justificar la esclavitud de los indígenas, entre otras razones. Esto ocurrió con especial frecuencia, cuando Carlos V contrató el arrendamiento de Venezuela con los Welser de Augsburgo en 1528, y dio libertad para tomar por esclavos a los indios "rebeldes" y "antropófagos" con el fin de venderlos (Salas, 1971: 37). Argumentos como este han generado la creencia de un supuesto atraso cultural entre la población que ocupaba la costa oriente de Venezuela. ${ }^{8}$

El criterio equivocado de un limitado desarrollo cultural entre las poblaciones prehispánicas que ocupaban gran parte del país se debe también a las visiones desacertadas que han generado las clasificaciones hechas por los estudiosos de la etnología antigua de Venezuela, como la de Julio César Salas. El referido autor planteó la existencia de dos grandes poblaciones en Venezuela: la que denominaba "La raza conquistadora", donde incluía a los caribes, además de a los teque, zapara, quiriquire, jirahara, maquiritare y motilón. Estas poblaciones ocupaban principalmente la costa central y oriental y parte del occidente del territorio venezolano. Según Salas, la principal característica que distinguía a estos grupos era 
la actitud guerrera: “...tribus belicosas, de costumbres feroces, nómadas muchas de ellas, de porte altivo é indómito, las cuales pedían su sustento á la caza y pesca únicamente..." (Salas, 1971: 33). Mientras que al otro grupo indígena lo denominaba "el antiguo ocupante de la tierra”, en el cual integraba a los arauca, achagua, saliva, alile o chama. Por el contrario estas poblaciones eran de “... modales y costumbres suaves, gente dócil, hospitalaria y poco guerrera que ignoraba el uso de envenenar sus flechas, agricultora é industriosa,..." (Salas, 1971: 32).

Otro aspecto que ha generado la confusión acerca de la descendencia étnica de la población que habitaba Paria a la llegada de Colón es el generalizado empleo del nombre caribe para referirse a la derivación lingüística de la población indígena que habitaba en la costa oriental de Venezuela. Este término fue utilizado por autores como Tavera Acosta (1907) y Tovar (1961), entre otros (Salas, 1971: 27).

El uso generalizado del término caribe para denominar indistintamente a los grupos indígenas que poblaban el oriente de Venezuela es cuestionado por Civrieux. El autor, basándose en las fuentes etnohistóricas aportadas por los colonizadores que vivieron con los indígenas durante los siglos XVII y XVIII, así como los misioneros Ruiz Blanco y Caolín y el gobernador de Nueva Andalucía, Pedro de Brizuela, contradice dicha generalización. Civrieux encontró que la lengua común a las poblaciones caribanas septentrionales presentaba grandes diferencias con la lengua kari ña, o caribe, de los indígenas de los llanos orientales del Guarapiche y de la Guayana, reconocidos como los verdaderos caribes (Civrieux, 1980: 40). Igualmente, el autor señala que los referidos lingüistas venezolanos no consideraron las diferencias dialectales que existían entre los diversos grupos étnicos que habitaban la costa del oriente de Venezuela y de los cuales van a dar cuenta los misioneros encargados de la evangelización de los indígenas durante los siglos XVII y XVIII (Civrieux, 1980: 35).
En su interés por elaborar una clasificación general de las poblaciones indígenas que habitaban en Venezuela, basada principalmente en las semejanzas culturales y geográficas, Acosta Saignes (1961) también incurrió en el error de incluir a la población autóctona que habitaba en el golfo de Paria, al igual que a la población del resto de la costa central y oriental de Venezuela, en la denominada Gran Área de los Caribes Orientales.

Igualmente Acosta Saignes generaliza cuando incluye a los indios de Paria en la subárea Cumanagoto, de la Gran Área de los Caribes Orientales. Según Civrieux, esta es una imprecisión en la interpretación de las fuentes históricas a la hora de ubicar geográficamente a los cumanagoto. Acosta Saignes (1961: 161) extiende el territorio de los cumanagoto desde el río Unare hasta las bocas del Orinoco. Mientras que Civrieux limita el territorio de los cumanagoto al extremo occidental de la provincia de Cumaná, o Nueva Andalucía, entre el río Neverí y el río Unare (Civrieux, 1980: 37). De esta forma, los indios paria quedaban fuera del área de los grupos indígenas que hablaban el dialecto cumanagoto y pertenecían al grupo de las tribus caribanas que hablaban el dialecto chaima en el extremo oriental (Civrieux, 1980: 37).

Sanoja y Vargas (1974: 159), basándose en la clasificación de las lenguas indígenas de Sur América de Loukotka, mantienen la denominación de caribes para los grupos indígenas que habitaban la región costera de Venezuela a la llegada de los conquistadores. Según los autores, en el oriente venezolano existía un conjunto de parcialidades integradas por: chaymas, cumanagotos, palenques, píritus, guayqueríes, parias, tomuzas, caracas, etc., que pertenecían lingüísticamente al grupo caribe, stock tamanaco, y presentaban entre sí diferencias en cuanto al grado de desarrollo cultural. Los autores reconocen la existencia de cierta homogeneidad cultural entre las poblaciones que habitaban la costa centro-oriental de Venezuela y clasifican a estas sociedades en la categoría de "centro-nuclear simple indiferenciado". 
Civrieux, por su parte, aporta elementos para clarificar la derivación étnica de las poblaciones indígenas que habitaban la costa del oriente de Venezuela durante el contacto. De acuerdo con el autor, la zona del oriente de Venezuela estaba poblada por numerosas tribus caribanas y el grupo étnico paria, como se ha denominado a la población que habitaba en la zona del mismo nombre; constituía una de las numerosas tribus que ocupaban la región. En la parte oriental de dicha franja, habitaban entre otros grupos los paria y chaima, en la parte occidental los cumanagoto y palenque, además de otras agrupaciones indígenas (Civrieux, 1980: 40). Todos estos grupos hablaban una lengua común denominada "chotomaimu", con varios dialectos locales que presentaban diferencias menores que no impedían la comunicación entre los grupos. Entre estos dialectos dos de los más importantes fueron el cumanagoto y el chaima, utilizados por los misioneros para la evangelización de numerosos grupos en el oriente de Venezuela (Civrieux, 1980: 38). Igualmente el autor señala que los grupos se autodenominaban "choto", que significa gente, persona humana. Este era un autogentilicio general, y a su vez cada grupo debió tener un gentilicio local para identificarse. También, es probable que otros grupos occidentales de la costa caribeña venezolana, como los caraca y meregoto, hablaran el mismo idioma chotomaimu (Civrieux, 1980: 40). El autogentilicio de los habitantes del golfo de Paria debió ser pariagoto, como señala Civrieux: "El sufijo goto en las lenguas Caribanas significa habitante de..., morador de..." (Civrieux, 1980: 37). Por esta razón, pariagoto debía significar habitante de Paria.

Otro criterio sobre la derivación étnica de las poblaciones que habitaban el golfo de Paria durante el período de contacto es el de Raggi (1973), quien plantea que en la zona de Paria residían indígenas pertenecientes al gran grupo Lucahio ${ }^{7}$ que poblaba la región de las Antillas Mayores y Menores, en la cuenca del Orinoco y la Guayana, hoy Guyana. El autor apoya su tesis en la existencia de semejanzas entre los indígenas lucahios y los naturales del golfo de Paria, en el comportamiento social, en el lenguaje y en elementos de la cultura material. Raggi cita a Las Casas, quien caracterizaba a los lucahios que se extendían por todas las islas al norte y sur de Cuba, como: "a. simples en el sentido de una cultura no complicada; b. pacíficos; c. benignos, es decir que no hacían mal a nadie; $d$. andaban desnudos o sea sin ropajes que luego encontraran en Tierra Firme" (Raggi, 1973: 38-39).

De lo anterior se interpreta que existen varios criterios sobre la derivación étnica de las poblaciones indígenas que habitan en el golfo de Paria cuando la llegada de los europeos. Sin embargo, el criterio con mayor fundamentación etnohistórica es el de Civrieux. Por tal razón, se concluye que los indígenas pariagoto constituían uno de los grupos étnicos que poblaban el oriente venezolano, conjuntamente con los cumanagoto, palenque y chaima. Estos grupos hablaban una misma lengua, aunque mantenían diferencias dialectales que no impedían la comunicación entre ellos. En el aspecto cultural, estas sociedades mantenían semejanzas con grupos étnicos de las Antillas y del Orinoco.

\section{Características culturales de los pariagoto durante el contacto}

Es difícil reconstruir las características culturales de los habitantes de Paria durante el contacto debido a varias razones. Una de estas es la inexistencia de información en las fuentes coloniales, ya que los colonizadores que llegaron al lugar se interesaron, principalmente, por controlar militarmente la zona, para luego remontar el río Orinoco en la búsqueda del supuesto Dorado (Aguado, 1987: 385-431). Otra razón que dificulta la reconstrucción de dicha cultura tiene que ver con la eliminación de un elevado número de indígenas de la Costa Oriental de Venezuela y el desarraigo de las comunidades nativas de su hábitat natural, así como la pérdida casi total de sus instituciones sociales, políticas y religiosas resultante de la violencia del contacto 
con la cultura europea, que tuvo como eje central la esclavitud de la población autóctona por parte de los perleros. Situación que ocurrió primero en Cubagua y luego en Margarita. Sin embargo, pese a las dificultades anotadas anteriormente, trataremos de reconstruir algunas características, y tomaremos como base la información etnológica contenida en el relato de Colón y los trabajos etnohistóricos realizados en la zona del oriente de Venezuela.

\section{a. Organización social}

A diferencia de otras poblaciones que habitaban en el norte de Suramérica donde las sociedades prehispánicas de cazadores-recolectores evolucionaron hacia la intensificación productiva y organización jerárquica en asociación con el cultivo del maíz, en la zona del oriente venezolano se desarrollaron comunidades locales de carácter igualitario que practicaban el cultivo del referido cereal. ${ }^{8}$

Encuanto ala ocupación delespacio,lascomunidades de Paria correspondían al tipo denominado por Sanoja y Vargas (1974: 161) "centros nucleares simples indiferenciados", en donde existían grandes casas comunales que podían albergar entre 600 y 4,000 indígenas. Esta característica es similar a la referida por Civrieux para el caso de otras tribus caribanas como los cumanagoto, donde la gran casa comunal constituía el poblado o unidad residencial. Esta forma ocupacional existe en algunos de los grupos étnicos caribanos actuales, como los e’niepá, yekuana y pemón (Civrieux, 1980: 148).

Aunque no se cuenta con datos demográficos precisos, puede decirse que durante el momento del contacto la zona de Paria estaba habitada por una numerosa población. Esta afirmación se basa en el mismo relato de Colón, donde resalta la elevada cantidad de indígenas que encontró en la tierra de Paria.

Según Sanoja y Vargas (1974: 148), la cantidad de población que integraba cada comunidad dependía de la disponibilidad de tierra que podían trabajar mediante una agricultura itinerante. Esta situación obligaba al desplazamiento de la vivienda o aldea hacia nuevas zonas de cultivo. También, Sanoja y Vargas (1974) señalan la práctica del abandono de la vivienda y construcción de una nueva cada ocho o diez años, como mecanismo para evitar la acumulación de desechos, entre las poblaciones del oriente de Venezuela. Sin embargo, Civrieux apunta la existencia de la costumbre de construir nuevas viviendas entre las tribus caribanas, pero como parte de los ritos especiales en ocasión de la muerte de jefes y simbolizando la formación de un nuevo gobierno (Civrieux, 1980: 144).

De acuerdo con Sanoja y Vargas, las comunidades que habitaban la zona del oriente de Venezuela en el período de la conquista correspondían al tipo semipermanente sedentaria, establecido durante el período prehispánico. Sin embargo, las comunidades halladas por los colonizadores presentaban una mayor complejidad en cuanto a la tecnoeconomía y al tamaño de las unidades sociales, con respecto a las prehispánicas (Sanoja y Vargas, 1974: 148). Lo que favorecía la estabilidad durante la mayor parte del año.

Cada aldea constituía una unidad social independiente basada en lazos de parentesco consanguíneos. Además, la densidad de población del grupo local estaba en relación con los enlaces matrimoniales que establecían con los pueblos vecinos. Las alianzas permitían afianzar la seguridad en los casos de conflicto y la independencia de nuevos "principales" o jefes de acuerdo con la magnitud de la parentela. Esta independización de los nuevos jefes residenciales sobre sus aliados se producía por sus cualidades militares, influencia política y poderes religiosos durante las contiendas bélicas (Civrieux, 1980: 142).

Según Caulín (citado por Civrieux, 1980: 143-144), las alianzas entre los grupos vecinos se incrementaron como resultado de la resistencia antiespañola. Debe agregarse que las alianzas intertribales tenían como 
base el intercambio de productos y se realizaban principalmente para enfrentar el peligro de guerra permanente entre los grupos (Langebaek, 1997: 147).

De acuerdo con Civrieux (1980: 144-145), la estructura familiar de los grupos caribanas era de tipo iroqués, en donde el tío materno se reconoce como padre. También, dentro de la organización social debió ser importante el levirato o matrimonio de la viuda con el cuñado, al igual que sucede actualmente entre las sociedades caribanas del Alto Orinoco. Sin embargo, según el mismo autor, entre estas sociedades se prohibía el levirato anticipado, como sucede con las poblaciones indígenas actuales (Civrieux, 1980: 145).

La poligamia se daba fundamentalmente entre los jefes como una manera de asegurar los nexos con el mayor número de aliados en caso de guerra (Civrieux, 1980: 146). No obstante, había una esposa principal, respetada y obedecida por las demás mujeres (Aguado, 1987: 17). La privilegiada era la primera, debido a su legalización por rituales matrimoniales que no ocurrían en los otros casos (Civrieux, 1980: 147).

La herencia de la jefatura en los grupos residenciales recaía sobre el hijo menor de la esposa principal, y en caso de muerte de este, heredaba el siguiente (Aguado, 1987: 17). Además el aspirante a jefe debía tener los méritos establecidos para la herencia del cargo (Civrieux, 1980: 144). También, los jefes residenciales tenían como privilegios la posesión de cotos privados de caza y pesca, en los cuales se prohibía la entrada de individuos comunes bajo pena de muerte y confiscamiento, como esclavos de los hijos y esposa del responsable (Aguado, 1987: 17).

Según Sanoja y Vargas (1974: 164) la integración sociopolítica en las comunidades indígenas del oriente de Venezuela variaba desde las comunidades más autosuficientes, con una autoridad interaldeas en tiempos de emergencia — en la parte occidental-, hasta las más jerarquizadas, con instituciones especiales para promover la integración del grupo en las comunidades que habitaban la parte oriental.
En la relación entre los sexos en la comunidad se establece el predominio de los hombres, expresado en la separación de los lugares de reunión de los varones, con respecto al de las hembras. Esta norma social se cumplía, en especial, en actividades, como el recibimiento de los forasteros y la comida (Civrieux, 1980: 148). Esta norma social fue identificada por los colonizadores europeos durante el primer contacto que establecieron con la población de Paria.

Otros de los aspectos característicos de la organización social de los grupos étnicos caribanos del pasado y del presente es la preponderancia de la familia extendida del grupo local sobre la familia nuclear, de esta forma la primera es la encargada de la responsabilidad educacional de los niños de la comunidad. Dentro de la familia extendida es importante el respeto y obediencia de los jóvenes y los adultos a los ancianos, encargados de la transmisión de las normas éticas, sociales y religiosas contenidas en los mitos. Este proceso de preparación para la vida adulta permite la integración del indígena a la sociedad y el tránsito a los diferentes estatus dentro de la misma (Civrieux, 1980: 148-149).

También, entrelasnormassocialesdelascomunidades caribanas están las referidas al comunitarismo en la realización de los trabajos - preparación del conuco, construcción de viviendas y embarcaciones, así como la participación en las expediciones estacionales de caza, pesca y recolección-. Igualmente, la distribución de alimentos se realizaba en forma comunitaria, en especial las piezas resultantes de la cacería eran distribuidas entre todos los miembros de la comunidad (Civrieux, 1980: 150-151). Esta característica es referida por fray Pedro Aguado entre los indios paragotos, ${ }^{9}$ cuando señala que: "Tenían por costumbre de hacerse muy grandes convites los unos a los otros, que comúnmente entre los españoles llaman borracheras; hacían en ellas muy grandes gastos; dábanse entre ellos muy grandes dádivas y presentes, conforme al posible que cada uno tenía..." (Aguado, 1987: 16). Las normas de cooperación recíproca se extendían hasta los grupos aliados. El 
ritual de recibimiento a los forasteros preveía, entre otros aspectos, el acceso al sitio de reuniones públicas en la vivienda, el saludo, el asiento y el agasajo de la bebida, considerado como un regalo muy preciado entre estas comunidades (Civrieux, 1980: 151-152). Este aspecto social de la población indígena de Paria ya fue reseñado en páginas anteriores en forma detallada en el relato de Colón sobre su tercer viaje a las Indias. También, fray Pedro de Aguado (1987: 17) refiere que otro aspecto del recibimiento dado por los indígenas a los españoles fue obsequiarles prendas de oro y los esclavos resultantes de la guerra con otros grupos. Sin embargo, esta característica tan conveniente a los intereses de los conquistadores no es referida por Colón en su relato sobre los habitantes del golfo de Paria.

\section{b. Economía y comercio}

De las fuentes consultadas se puede inferir que los pariagoto poseían una amplia base económica integrada por diversas actividades como la agricultura, la pesca marina, la caza terrestre y la recolección de frutos. De esta característica da cuenta el relato de Colón y de cronistas como fray Pedro de Aguado. Este último autor señalaba acerca de los indios - paragotos - pariagotos, que era: “...gente muy proveída de todo género de comida, así de carnes monteses como de pesquería y mantenimientos de la tierra y todo género de aves..." (Aguado, 1987: 16).

Las actividades económicas estaban regidas por el ciclo anual climático entre los meses secos y los lluviosos - verano e invierno-. Por ejemplo durante el verano, cuando los ríos eran navegables, se realizaba el mayor intercambio de productos entre las tribus, por medio de expediciones y viajes, mientras que en el invierno se dedicaban al inicio de la siembra, a la fabricación de objetos — cestas, chinchorros, canoas, armas, entre otros - destinados al intercambio el siguiente verano y al descanso (Langebaek, 1997: 144145).
A las actividades productivas se agregaba el intenso comercio que se realizaba con las poblaciones de la costa y del interior en el área de intercambio comercial caribana, que se extendía en la costa hasta las Antillas y en tierra adentro hasta la cuenca del Orinoco. Los habitantes de la costa abastecían de sal y pescado a los del interior. Mientras que las poblaciones que habitaban en el interior ofrecían a cambio los productos agrícolas y de carne de cacería. Además de otros productos que se intercambiaban en el área caribana, como el hayo o coca (Eritroxilaceas), que cultivaban los indios tomuza de la serranía del interior — actual estado Miranda-; la guarema, planta tintórea que también cultivaban los tomuza, y el veneno de guerra cumanagoto, entre otros artículos. Por su parte, los indígenas de Paria debieron obtener por trueque estos productos a cambio de algunos artículos, como la serpentina. Este material era utilizado por las poblaciones caribanas para la fabricación de instrumentos como las hachas de mano y las azuelas empleadas en la limpieza del conuco (Civrieux, 1980: 169-170). La península de Paria es una de las zonas donde existen afloramientos de serpentina, además de otras zonas como la cordillera del Interior, la península de Araya y el norte de la isla de Margarita. ${ }^{10}$

En los conucos se cultivaba una serie de plantas entre las cuales figura el maíz (Zea mays) como el principal producto, del cual poseían muchas variedades ${ }^{11} y$ consumían molido en forma de pan, asado y como bebida ritual fermentada denominada "itoco". También, cultivaban la yuca (Manihot esculenta) dulce y amarga. Esta última era más frecuente, ya que se utilizaba para la preparación del casabe, principal bastimento de viaje. Para el siglo XVII los rallos utilizados en la confección del casabe eran de hojalata y los budares de hierro, lo que indica la rápida transculturación producida por el metal de los conquistadores (Civrieux, 1980: 155157). Además, otros tubérculos como la batata (Ipomea batata), el mapuey y el ñame, eran importantes en la alimentación de estas poblaciones. No está claro si los Paria cultivaban el algodón (Gossypium hisutum) 
o recolectaban el que crecía en forma silvestre en la tierra, debido a la preferencia que tenían por el maguey o fique para la fabricación de tejidos (Sanoja y Vargas, 1974: 162). Sin embargo, el uso generalizado de los pañuelos de algodón, referido por Colón, indica un aprovisionamiento relativamente cercano del material.

La recolección de frutas silvestres suplía la escasez de plantas cultivadas y eran utilizadas como bastimento en los largos viajes. Además numerosas plantas se utilizaban para la fabricación de artesanías, la farmacopea y las prácticas mágicas (Civrieux, 1980: 154). Recolectaban una gran variedad de frutas silvestres entre las cuales estaban la guanábana (Annona muricata L.sp.), mamón(Meliococabijuga L.sp.), guamo (Minosaceas, del género Inga), icacos (Chrysobalanus icaco L. sp.), jobos (Spoindias luteas L. sp.), y tunas (Opuntia sp.) (Sanoja y Vargas, 1974: 162). Algunas de estas frutas eran utilizadas para la preparación de bebidas, reseñadas en el relato de Colón como vinos de frutas. También en la economía de algunas de las poblaciones del oriente del país era importante la domesticación de las abejas para la recolección de la miel (Civrieux, 1980: 154).

La organización de las actividades económicas se basaba en la división por sexos. Civrieux (1980: 155) señala que la caza y la pesca eran exclusivamente masculinas, mientras la agricultura era compartida por los hombres y las mujeres; los primeros se encargaban de la preparación del conuco, la siembra y la limpieza, y en la recolección participaban ambos. A diferencia del autor anterior, Sanoja y Vargas (1974: 162) plantean que la mayor parte de las tareas agrícolas recaían sobre las mujeres, además de la mayor parte de las actividades domésticas, como la preparación de la comida, el tejido y la fabricación de vasijas de barro.

\section{c. Creencias mágico-religiosas}

De acuerdo con Civrieux, la vida cotidiana de los caribanos ha estado íntimamente relacionada con sus creencias mágico-religiosas. El pasaje por las diferentes etapas del ciclo de vida, el nacimiento, la pubertad y la muerte, se realizaba con base en una serie de ritos que guardaban una relación estrecha con la religión (Civrieux, 1980: 173-178). La máxima autoridad religiosa era el shaman, quien intervenía en especial en las situaciones de emergencia de la comunidad y en los ritos de desfloración de las vírgenes de la comunidad así como en los matrimonios (Civrieux, 1980: 176-177). Igualmente, los shamanes participaban en los ritos propiciatorios de la caza y de la pesca y en las actividades de curación y adivinatorias, para lo cual utilizaban drogas intoxicantes como el tabaco y el "yopo" (Sanoja y Vargas, 1974:165). En cuanto a la participación de los shamanes en los actos colectivos y en las curaciones, difiere Civrieux (1980: 194) al plantear que eran los ancianos de la comunidad los que participaban en estos ritos, al igual que en aquellas curaciones que no eran producidas por hechizos y que se curaban con hierbas y raíces. Generalmente, el papel de shaman lo desempeñaba una persona diferente a la del jefe, y requería de una preparación especial que era ofrecida por otro shaman (Sanoja y Vargas, 1974: 165).

Los ritos fúnebres se diferenciaban según el rango social del difunto. En el caso de los caciques o jefes principales, las ceremonias duraban varios días y se practicaba el desecamiento al fuego del cadáver, la conversión en ceniza y el consumo colectivo de esta, rito que se acompañaba con un gran festín. En el caso de los individuos comunes, eran por lo general enterrados con sus pertenencias; al año los huesos eran desenterrados y posteriormente quemados (Sanoja y Vargas, 1974: 165).

En general, fueron las creencias y prácticas religiosas de las poblaciones caribanas las que generaron la mayor parte de las interpretaciones equivocadas por parte de los colonizadores, como el "endocanibalismo", intrerpretación que hizo el colonizador del consumo ritual comunitario de las cenizas de los difuntos, mezcladas con alguna bebida. Igualmente, fueron tergiversadas las concepciones indígenas sobre el alma y los espíritus, que entendían como el doble invisible que servía de compañero durante la vida. Los colonizadores 
proyectaron sus creencias mágico-religiosas sobre los indígenas y equipararon a los shamanes con los brujos del viejo mundo, bajo el argumento de que tenían comercio con el diablo (Civrieux, 1980: 180-185). Tampoco, entendieron la costumbre de la embriaguez ritual (Civrieux, 1980: 150), que identificaban, como lo hacía Aguado, con las borracheras entre los españoles (Aguado, 1987: 16).

Otra de las características culturales de las poblaciones caribanas de la costa de Venezuela y de las Antillas era el juego de pelota. Algunas de las fuentes consultadas coinciden en señalar la importancia de este rasgo social entre varios de los grupos étnicos de Venezuela y las Antillas (Raggi, 1973: 45; Strauss, 1998: 29), que en ciertos casos adquiría carácter míticoreligioso. Igualmente la población que habitaba en Venezuela durante el período de contacto expresó su creatividad en numerosas manifestaciones como adivinanzas, consejos de los ancianos, interpretaciones de los sueños, presagios, poemas, leyendas y mitos (Strauss, 1998: 30).

\section{Etnohistoria de los pariagoto (siglos XVI, XVII y XVIII)}

En esta parte del trabajo sistematizaremos algunos de los acontecimientos sociohistóricos que se produjeron durante la conquista y la colonización de la costa del oriente de Venezuela en los siglos XVI, XVII y XVIII, donde participaron los indígenas pariagoto. Debe aclarase que, a diferencia de otros grupos indígenas del oriente de Venezuela como los cumanagoto, evangelizados por monjes observantes, y de los cuales los misioneros dejaron información etnológica que ha permitido la reconstrucción de algunos de los cambios ocurridos en el contacto con el colonizador europeo; en el caso de los indígenas pariagoto no sucedió de esta manera (Civrieux, 1980:56), por lo que la reconstrucción de la etnohistoria del referido grupo étnico es bastante difícil.
En 1530 se produjo el alzamiento de los indios de Paria o "Uriaparia"12 contra los españoles, específicamente contra Antonio Sedeño, gobernador de Trinidad, y sus hombres (Aguado, 1987: 385-386).

Durante la primera mitad del siglo XVI, al igual que otras poblaciones de la costa del oriente de Venezuela, los indígenas de Paria fueron sometidos a la esclavitud para el rescate de perlas (Aguado, 1987: 447). De acuerdo con las fuentes consultadas, como resultado de las acciones violentas de los rescatadores de perlas, la costa que se extiende desde Paria hasta Curiana - hoy estado Falcón- quedó casi despoblada y destruida. A esta situación se sumaban las expediciones militares en busca de "El Dorado", que destruían las poblaciones indígenas que encontraban a su paso.

Desde la península de Paria se realizaron varias expediciones hacia la Guayana en busca de "El Dorado", la primera por Diego de Ordaz en 1532, quien remontó el río Orinoco (Aguado, 1987: 415). Debido a las limitaciones de abastecimiento y a los constantes ataques de los indígenas de la zona, el capitán decidió regresar a la costa de Paria y realizar la expedición por Cumaná (Aguado, 1987: 431). También Ortal, el sucesor de Diego de Ordaz como gobernador de Paria, emprendió en 1535 la misma expedición, además de otros colonizadores que lo secundaron (Aguado, 1987: 485-486).

El despoblamiento por la violencia de la conquista impidió la creación de poblados coloniales en la península de Paria y en el resto de la costa del oriente de Venezuela durante la mayor parte del período colonial. En el caso de los pariagoto, estos huyeron y se internaron en Guayana hasta las altiplanicies y sabanas de la zona de Upata, en donde fueron adoctrinados por los misioneros catalanes.

Durante la segunda mitad del siglo XVI y la primera mitad del siglo XVII, se produjeron las rivalidades entre las órdenes misioneras de los franciscanos observantes y capuchinos por la evangelización de los indígenas del oriente de Venezuela. Los franciscanos querían consolidar el monopolio de la evangelización

100 Revista LiminaR. Estudios sociales y humanísticos, año 8, vol. VIII, núm. 2, diciembre de 2010, San Cristóbal de Las Casas, Chiapas, México. ISSN: 1665-8027 
en las Indias e impedían la entrada a los misioneros capuchinos a la región. El interés de "poblarlos" en misiones, sometiéndolos efectivamente a las leyes del reino, además de la motivación evangelizadora (Civrieux, 1980: 92-93), se explicaba por el peligro que suponía para la dominación española el acecho de los franceses desde las Antillas Menores y de los holandeses por el Esequibo, y que los mismos convirtieran a las poblaciones indígenas en sus aliados. Los franceses practicaban el comercio ilícito de poitos o esclavos con los caribes, a través de los ríos Cuyuní y Mazarini en la Guayana (Carrocera, 1979: 21-23).

En 1687, cuando se produjo la fundación de las misiones en Guayana, por parte de los capuchinos catalanes, fueron hallados grupos de indígenas pariagoto en dicho territorio. Estos se encontraban situados en tierras próximas a la ciudad de Guayana, y además en las riberas del Caroní y del Paragua. Con las referidas poblaciones indígenas fueron fundadas varias misiones en la región. Una de las misiones fundadas por los capuchinos fue la de San Antonio de Papua, en 1725, en la zona del Caroní. La referida misión se estableció con nueve familias de indios pariagoto. En 1728 la población fue atacada por una epidemia de viruela, que se propagó desde la misión de la Inmaculada Concepción de Suay, muriendo algunos indígenas. Sin embargo, pese a los efectos de la epidemia, la misión capuchina en el Caroní permaneció (Carrocera, 1979: 21-23). También, fueron encontrados algunos indígenas pariagotos distribuidos en otras zonas de la Guayana, y debido al reducido número de estos fueron poblados conjuntamente con otros grupos de naturales (Bruno de Barcelona, citado por Carrocera, 1979: XV). De acuerdo con las fuentes, las misiones capuchinas de Guayana fueron elogiadas por las propias autoridades coloniales, debido a los métodos educativos que utilizaban. Según estas, los misioneros preparaban a los indígenas en una serie de oficios, como albañilería, carpintería, forjado de hierro, tejido de pieza de vestir y en la actividad agropecuaria. Igualmente, los misioneros se esforzaban porque los indios tuvieran sus propias labranzas de maíz, yuca, arroz, plátano y algodón. Además, en las misiones se criaba ganado vacuno, caballar y mular. También existían escuelas donde los religiosos enseñaban a los muchachos la lectura, la escritura y la música. Debe agregarse que, según las fuentes, era la única misión donde la evangelización era bilingüe (Carrocera, 1979: XXIII-XXIV). La actuación de las misiones capuchinas en Guayana finalizó en 1817, después de fundar 52 pueblos con 21,246 habitantes, de los que subsistieron 28 hasta 1817, y de estos se han conservado algunos hasta el presente (Arellano, 1986: 205).

Un dato que indica la importancia de la población indígena pariagoto en las misiones de Guayana es que el P. Miguel Ángel de Gerona, uno de las misioneros capuchinos catalanes, para facilitar la evangelización de la referida población compuso el Diccionario Pariagoto, titulado: "Breve compendio de nombres sustantivos y adjetivos o términos más comunes y necesarios para entender la lengua pariagota por el abecedario con algunas notas y advertencias" (Carrocera, 1979: XXI).

Los anteriores son algunos de los pocos párrafos en las fuentes históricas coloniales de Venezuela donde se hace mención de los indios pariagoto. Queda por buscar en la memoria de sus descendientes aspectos que la arqueología y los cronistas no han podido informar.

\section{Conclusiones}

1. El estudio etnohistórico de la población indígena del extremo oriental venezolano que toma en cuenta una visión interdisciplinaria, donde se integra la historia, la antropología y la arqueología, nos permite historiar procesos, hechos y experiencias que se dieron en esa región de Venezuela durante la conquista y colonización europea, en presencia de la diversidad de lo social y cultural. En este contexto, el contrastar y combinar la información contenida en las fuentes nos ayuda a tener una visión de la diversidad de los grupos humanos que habitaron la región, sus especificidades socioculturales 
y su historia. En este análisis adquiere relevancia el relato de Colón, que pese a las interpretaciones etnocéntricas constituye la primera información que se tiene sobre las características socioculturales de los pariagoto en el período de contacto. Así también se pueden establecer algunas correspondencias con lo planteado en las fuentes antropológicas y arqueológicas.

2. El análisis de los pariagoto como fenómeno histórico particular que se desarrolla en un contexto natural y social en que se integran variables ecológicas, económicas, organizativas, políticas e ideológicas, a partir de la combinación de las fuentes históricas, arqueológicas y etnológicas, nos permite tener una visión más integral de su cultura y los cambios que esta experimentó en el tiempo. Igualmente nos permite aclarar falsas visiones y confusiones que se han elaborado sobre estas poblaciones y un supuesto limitado desarrollo cultural con respecto a otras regiones de América. Si bien estas sociedades no construyeron obras monumentales de infraestructura, en su desarrollo le dieron prioridad a dos aspectos, como el de las alianzas con sus vecinos y las creencias mágico-religiosas. Estos dos factores socioculturales son de gran importancia en la construcción del proceso civilizatorio de la región oriental del país y constituyen parte de ese pasado múltiple y complejo que subyace a la identidad nacional del venezolano.

3. A diferencia de lo que ocurrió durante la conquista en otras zonas de Venezuela, en donde se aplicó la normativa colonial y se produjo la concentración de los indígenas en pueblos para su adoctrinamiento y aculturación, en la zona de Paria y gran parte del oriente venezolano no ocurrió así; a raíz de la violencia de la conquista europea predominó el despoblamiento resultante de la esclavitud y la guerra. Los indígenas, huyendo de los conquistadores, se internaron en zonas inaccesibles del suroriente de Venezuela, por lo que los descendientes de aquellos que lograron sobrevivir integran parte de los grupos étnicos que habitan actualmente en esa zona del país.

\section{Notas}

${ }^{1}$ Arellano se refiere a 1498 como la fecha oficial del descubrimiento de la Tierra Firme de América del Sur. El autor basa su afirmación en el libro de Juan Manzano (1972) donde presenta las pruebas de que en el tercer viaje Colón llego a las costas de Paria y descubrió la Tierra Firme de América.

${ }^{2}$ Según el Diccionario de la Real Academia de la Lengua Española (1992: 1929), "tablachina" significa escudo de madera, también denominado broquel.

${ }^{3}$ Samuel Eliot Morison mantuvo por largo tiempo una especie de monopolio norteamericano sobre Colón. Estudió con pericia la ruta seguida por el almirante, pero no así interpretó el papel y las condiciones de la época; hace aparecer a Colón y sus hombres como: “... valientes y galantes representantes de la Cámara de Comercio, que llevan el buen sentido y el alegre cristianismo a un nuevo continente" (Koning, 1991: 137).

${ }^{4}$ Hans Koning (1991: 77) señala que, durante el segundo viaje de Colón, los desmanes y atropellos cometidos por los conquistadores con los indígenas en su afán de buscar oro transformaron las iniciales relaciones amistosas en hostiles: “...La simulación había terminado, se había acabado el idilio. A los indios, que habían sido alabados por su generosidad e inocencia, ahora se les llamaba salvajes. Se habla de esclavitud y de oro más que hermandad y conversión".

${ }^{5}$ Zubiri señala que esa distorsión de la historia se inició desde los comienzos de la colonización, debido a las confusiones de los primeros cronistas, comenzando con Bartolomé de Las Casas, que sirvieron de fuente a los distintos historiadores.

${ }^{6}$ Sin embargo, esta visión estereotipada que tenían los europeos del caribe insular como comedor de carne fresca, de instinto belicoso, aventurero, sanguinario, cruel y antropófago, fue aprovechada por los indígenas 
como identidad étnica en la resistencia al dominio colonial (Amodio, 1999: 9-29).

${ }^{7}$ Según el padre Las Casas, que utilizó los originales del diario de Colón, el almirante refería las Bahamas como islas de los lucahios (Raggi, 1973: 35).

8 Langebaek explica los factores ambientales y socioeconómicos que incidieron en las transformaciones y el desarrollo de las distintas sociedades del nororiente de Colombia y norte de Venezuela (1997: 66-76).

${ }^{9}$ Aguado (1987: 15) utiliza el nombre paragoto para referirse a una de las tribus del oriente venezolano; este grupo corresponde a los pariagoto, ya que en el mapa donde Civrieux identifica las tribus vecinas a los cumanagoto durante el período de la conquista no se incluye ningún grupo paragoto.

${ }^{10}$ La extensión del comercio de la serpentina hallada en el oriente de Venezuela debió llegar hasta zonas muy distantes, como los Andes venezolanos, donde fabricaban los pendientes alados. Este es un indicador, de la amplitud de las redes de comunicación existentes durante el período prehispánico en Venezuela (Wagner, 1980: 25).

${ }^{11}$ De Civrieux, citando a Ruiz Blanco (1980: 155-156), señala nueve variedades de maíz que cultivaban las tribus caribanas de Venezuela: blanca, para asar, blanca y negra, maíz "largo", color ceniza, y el llamado por los españoles maíz Cariaco, mientras que los cumanagotos lo llamaban erepa.

${ }^{12}$ Aguado (1987: 383) utiliza la denominación "costa de Tierra Firme y provincia o punta de Uriaparia" para referirse a la costa del golfo de Paria en el oriente de Venezuela. También refiere el nombre de Uriaparia para la zona correspondiente al bajo Orinoco, mientras que en la parte del río arriba adquiría el nombre de Orinoco (1987: 421).

\section{Bibliografía}

Acosta Saignes, Miguel (1961), Estudios de etnología antigua de Venezuela; Caracas, Venezuela: Universidad Central de Venezuela.
Aguado, fray Pedro de (1987), Recopilación historial de Venezuela, en Fuentes para la Historia Colonial, Tomo I, Caracas, Venezuela: Biblioteca de la Academia Nacional de la Historia.

Amodio, Enmanuele (1999), "Los caníbales mutantes. Etapas de transformación étnica de los caribes durante la época colonial", en Boletín Americanista, Barcelona-España, año II, núm. 49.

Arellano, Fernando (1986), Una introducción a la Venezuela prehispánica, Caracas, Venezuela: Universidad Católica Andrés Bello.

Arvelo, Liliam y Wagner, Erika (1984), "Relaciones estilísticas cerámicas del noroeste de Suramérica con las Antillas", en Erika Wagner: Relaciones prehispánicas de Venezuela, Caracas, Venezuela: Acta Científica Venezolana..

Boletín de la Academia Puertorriqueña de la Historia, 1984, "Perspicacia del Almirante al identificar a los caribes", vol. VIII, núm. 31, enero 1984, Puerto Rico, pp. 271-276.

Carrocera, Buenaventura de (1979), Misión de capuchinos en Guayana, Fuentes para la Historia Colonial, Tomo II, Caracas, Venezuela: Biblioteca de la Academia Nacional de la Historia.

Colón, Cristóbal (1989), Textos y documentos completos, relaciones de viajes, cartas y memorias, Madrid, España: Alianza Editorial.

Civrieux, Marc De (1980), "Los Cumanagotos y sus vecinos", en Los aborígenes de Venezuela, Volumen I, Caracas, Venezuela: Fundación La Salle.

Cruxent, José M. y Rouse, Irving (1961), Arqueología cronológica de Venezuela, Caracas, Venezuela: Ernesto Armitano Editor.

Koning, Hans (1991), Colón, Buenos Aires, Argentina: Ediciones de La Flor.

Langebaek Carl (1997), Noticias de caciques muy mayores, Medellín, Colombia: Editorial Universidad de Antioquia.

Lehmann, H. (1973), Las culturas precolombinas, Buenos Aires, Argentina: EUDEBA. 
Manzano, Juan (1972), Colón descubrió América del Sur en 1494, Caracas, Venezuela: Academia Nacional de la Historia.

Raggi, Carlos (1973), "Los indios lucahios en las Antillas Menores", en Proceedings of the fifth International Congress for study of pre-columbia cultures of the lesses Antillas, Antigua, july 1973, pp. 22-28.

Salas, Julio César (1971), Etnología e historia de Tierra Firme, Caracas, Venezuela: Publicaciones de la Universidad Central de Venezuela.

Sanoja, Mario y Vargas, Iraida (1974), Antiguas formaciones y modos de producción venezolanos, Caracas, Venezuela: Monte Ávila Editores.

Strauss, Ruperto (1998), "Venezuela prehispánica”, en Repaso de la historia de Venezuela, Caracas, Venezuela: Comisión Presidencial V Centenario de Venezuela.
Vila, Marco Aurelio (1976), Notas sobre geoeconomía prehispánica de Venezuela; Caracas, Venezuela: Ediciones de la Facultad de Humanidades y Educación, Universidad Central de Venezuela.

Wagner, Erika (1980), La prehistoria de Mucuchies, Caracas, Venezuela: Universidad Católica Andrés Bello.

Zubiri Marín, María Teresa (1991), "La historia escrita por los cronistas o el falseamiento de la historia de Venezuela (s. XVI-XVII)", en Conquista y resistencia en la historia de América, Barcelona, España: Universidad de Barcelona.

Zucchi, Alberta (1984), "Nueva evidencia sobre penetración de Grupo Cerámica a las Antillas Mayores", en Relaciones prehispánicas de Venezuela, Acta Científica Venezolana, Caracas, Venezuela.

\section{Mapa 1. Ubicación del Golfo de Paria en el extremo oriental de Venezuela}

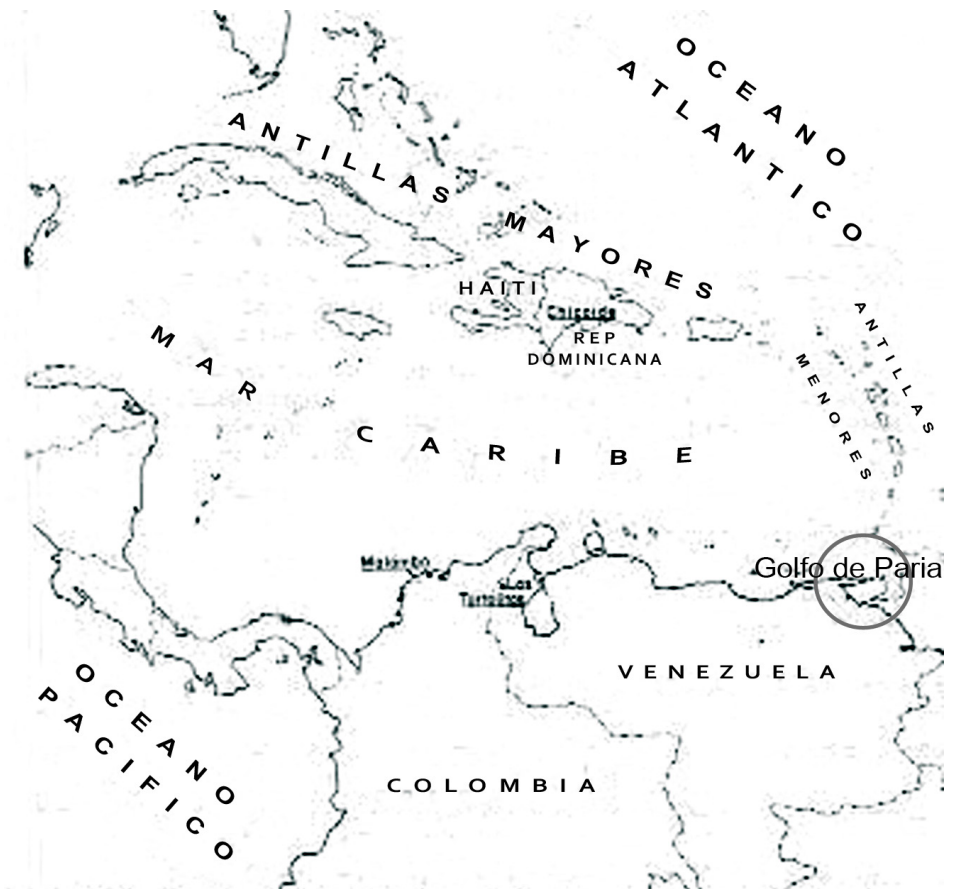




\section{Mapa 2. Ubicación del grupo étnico de los Paria en el extremo oriental de Venezuela}

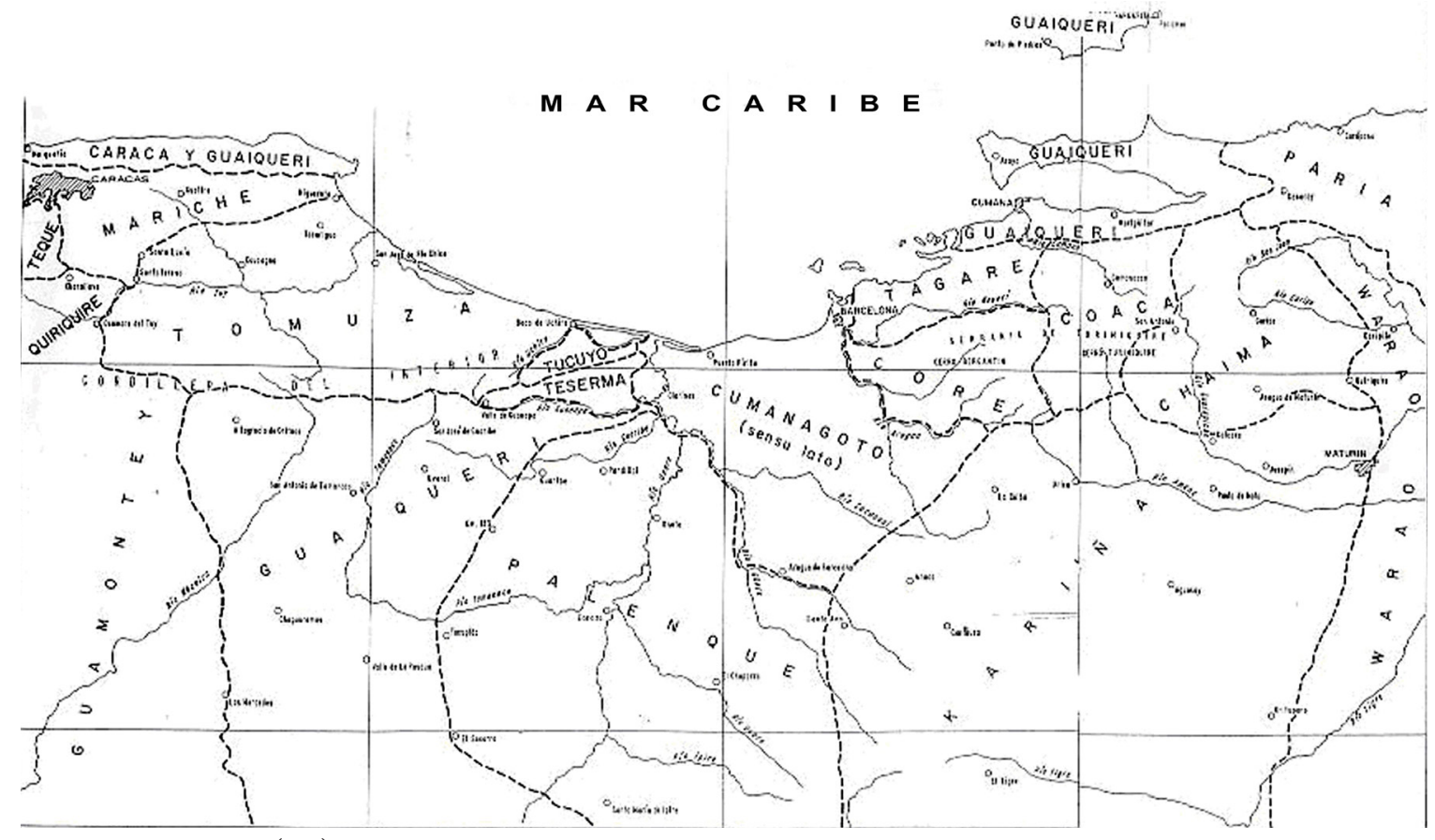

Fuente: Civrieux, 1980 (s.n.) 